\title{
LRRK2 Mutations and Asian Disease-Associated Variants in the First Parkinson's Disease Cohort from Kazakhstan
}

\author{
Rauan Kaiyrzhanov (D), ${ }^{1}$ Akbota Aitkulova $\left(\mathbb{D}^{2},{ }^{2}\right.$ Chingiz Shashkin $(\mathbb{D})^{3}$ \\ Nazira Zharkinbekova $\mathbb{D}^{\mathbb{D}},{ }^{3}$ Mie Rizig, ${ }^{1}$ Elena Zholdybayeva ${ }^{(D)},{ }^{2}$ Zharkyn Jarmukhanov $\mathbb{D}^{\circ},{ }^{2}$ \\ Vadim Akhmetzhanov $\mathbb{D}^{3}{ }^{3}$ Gulnaz Kaishibayeva $\mathbb{D}^{4}{ }^{4}$ Talgat Khaibullin $\left(\mathbb{D},{ }^{5}\right.$ \\ Altynay Karimova (D), ${ }^{4}$ Serik Akshulakov $\mathbb{D}^{6}{ }^{6}$ Askhat Bralov ${ }^{(D)}{ }^{6}$ Nurlan Kissamedenov $\mathbb{D}^{6}{ }^{6}$ \\ Zhanar Seidinova $\mathbb{D}^{3},{ }^{3}$ Anjela Taskinbayeva $(\mathbb{D})^{3}$ Aliya Muratbaikyzy $\mathbb{D D}^{3}{ }^{3}$ \\ and Henry Houlden ${ }^{1}{ }^{1}$
}

\footnotetext{
${ }^{1}$ University College London, Institute of Neurology, Department of Neuromuscular Disorders, Queen Square, WC1N 3BG, London, UK

${ }^{2}$ National Center for Biotechnology, Department of Molecular Genetics, 13/5 Korgalzhyn Avenue, 01000 Nur-Sultan, Kazakhstan

${ }^{3}$ South Kazakhstan Medical Academy, Department of Neurology, 1/1Al-Farabi Avenue, 160019 Shymkent, Kazakhstan

${ }^{4}$ Institute of Neurology Named After S. K. Kaishibayev, 9a Mamur 4 Micro-district, 050000 Almaty, Kazakhstan

${ }^{5}$ Semey Medical University, Department of Neurology, 103 Abai Street, 071400 Semey, Kazakhstan

${ }^{6}$ National Center for Neurosurgery, 34/1 Turan Avenue, 01000 Nur-Sultan, Kazakhstan
}

Correspondence should be addressed to Henry Houlden; h.houlden@ucl.ac.uk

Received 23 November 2019; Accepted 31 December 2019; Published 19 February 2020

Academic Editor: Carlo Ferrarese

Copyright (c) 2020 Rauan Kaiyrzhanov et al. This is an open access article distributed under the Creative Commons Attribution License, which permits unrestricted use, distribution, and reproduction in any medium, provided the original work is properly cited.

\begin{abstract}
Background. LRRK2 mutations have emerged as the most prevalent and potentially treatable determinants of Parkinson's disease (PD). Peculiar geographic distribution of these mutations has triggered an interest in genotyping PD cohorts of different ethnic backgrounds for LRRK. Objective. Here, we report on the results of LRRK2 screening in the first Central Asian PD cohort. Methods. 246 PD patients were consecutively recruited by movement disorder specialists from four medical centers in Kazakhstan, and clinicodemographic data and genomic DNA from blood were systematically obtained and shipped to the Institute of Neurology University College London together with DNAs from 200 healthy controls. The cohort was genotyped for five LRRK2 mutations (p.Gly2019Ser, p.Arg1441His, p.Tyr1699Cys, p.Ile2020Thr, and p.Asn1437His) and three East Asian disease-associated variants (p.Gly2385Arg, p.Ala419Val, and p.Arg1628Pro) via Kompetitive allele-specific polymerase chain reaction assay analysis. Results. None of the study subjects carried LRRK2 mutations, whereas the following Asian variants were found with insignificant odds ratios (OR): p.Gly2385Arg (1.2\%, minor allele frequency (MAF) 0.007, OR 1.25, $p=0.8$ ), p.Ala419Val (3.7\%, MAF 0.02, OR $1.5, p=0.4$ ), and p.Arg1628Pro was found only in $1 \%$ of controls. p.Gly2385Arg was positive in a big family with PD and tremor, although with incomplete segregation. One early-onset PD subject was homozygous for p.Ala419Val who developed fast progression and severe dyskinesias. p.Ala419Val was associated with early-onset PD. Conclusions. We showed that East Asian LRRK variants could be found in Central Asian populations but their pathogenicity remains to be elucidated in larger PD cohorts.
\end{abstract}

\section{Introduction}

The important recent achievement in Parkinson's disease (PD) research has been the identification of several causative and risk genes with their putative functions. Leucine- rich repeat kinase 2 (LRRK2) gene has been distinguishable from other known PD genes with a number of functional and epidemiologic features. LRRK2 is a highly conserved and widely expressed gene that encodes a unique multifunctional and multidomain protein, named dardarin [1]. 
TABle 1: Clinical and demographic characteristics of the cohort.

\begin{tabular}{|c|c|c|}
\hline & Cases & Controls \\
\hline Number & 246 & 200 \\
\hline Ethnic groups, abs number (\%) & $\begin{array}{c}\text { Kazakhs } 179(72.8 \%) \\
\text { Russians } 51(20.7 \%) \\
\text { Uygurs } 7(2.8 \%) \\
\text { Tatars } 5(2 \%) \\
\text { Koreans } 3(1.3 \%) \\
\text { Tajiks } 1(0.4 \%) \\
\end{array}$ & \\
\hline Sex distribution & $\begin{array}{c}\text { Males }-120, \text { females }-126 \\
\text { M : F ratio- }-0.95: 1\end{array}$ & $\begin{array}{c}\text { Males-62, females-138 } \\
\mathrm{M}: \mathrm{F} \text { ratio } 0.4: 1\end{array}$ \\
\hline Age at examination (mean) & $\begin{array}{l}\quad 61.7 \pm 10.3(\text { range } 28-83) \\
\text { For males-60.3 } \pm 10.6(\text { range } 28-82), p=0.03 \\
\text { For females-63.1 } \pm 9.9(\text { range }-32-83)\end{array}$ & $\begin{array}{c}\text { Mean age-54.93 } \pm 4.8(47-66) \\
\text { For males-55.27 } \pm 4.8(47-66) \\
\text { For females-54.78 } \pm 4.7(47-65)\end{array}$ \\
\hline Age of onset (mean) & $\begin{array}{c}\mathbf{5 5 . 0 6} \pm 11.15(\text { range } 14-77) \\
\text { For males-53.3 } \pm 11.9(\text { range } 14-76), p=0.01 \\
\text { For females-56.8 } \pm 9.9(\text { range } 26-77)\end{array}$ & \\
\hline Disease duration (mean) & $13.2 \pm 9.3($ range $1-24)$ & \\
\hline HY stage off (mean) & $\begin{array}{l}2.4 \pm 0.6(\text { range } 1-5) \\
\text { For males }-2.3 \pm 0.7 p=0.6 \\
\quad \text { For females }-2.4 \pm 0.6\end{array}$ & \\
\hline Family history of PD and tremor, abs number (\%) & $21(8.5 \%)$ & \\
\hline Young-onset cases, abs number (\%) & $\begin{array}{l}31(12.6 \%) \text { before the age of } 40 \\
65(26.4 \%) \text { before the age of } 50\end{array}$ & \\
\hline
\end{tabular}

$\mathrm{M}: \mathrm{F}-$ male to female.

Dardarin is a complex chain of 2527 polypeptides containing two distinct enzymes, namely protein kinase and guanosine triphosphatase (GTPase), as well as multiple protein interaction domains [2]. These domains might interact with each other and other cell signaling proteins, thus playing a putatively key role in cellular function [3-5].

Intriguing is the fact that almost every LRRK2 domain is susceptible to $\mathrm{PD}$-associated mutations resulting largely in idiopathic PD- (iPD-) like phenotype and pleomorphic neuronal pathology $[2,4]$. Amongst the number of known LRRK2 mutations, p.Gly2019Ser mutation has emerged as an important determinant of familial autosomal dominant PD and iPD in North African Arabs, Ashkenazi Jews, and to a lesser degree in European and North American populations [6].

Interestingly, it appears that some LRRK2 mutations and disease-associated variants are specific to particular ethnic groups, most likely due to common founder effects [7]. This is evidently applicable to p.Gly2019Ser mutation, which is common in PD patients from the Western hemisphere and has not yet been reported in the big PD cohorts from East Asia. Similarly, several PD risk variants of LRRK2 including p.Gly2385Arg, p.Ala419Val, and p.Arg1628Pro have only been reported in East Asian populations and have been absent in the Western PD cohorts [8].

PD genetics has been largely unexplored in several world regions, including Central Asia. Here, we investigate 8 LRRK2 mutations and East Asian risk variants in an interesting population residing between Europe and Asia, in the first cohort of PD patients and healthy controls from Kazakhstan.

\section{Study Methodology}

2.1. Study Subjects. A total of 246 PD patients were consecutively recruited, with no regard to nationality, during 14 months from the National Center for Neurosurgery in NurSultan city, movement disorders clinics in Almaty city, and a regional hospital in Shymkent city in Kazakhstan. The diagnoses of clinically established and clinically probable PD were made on the basis of the agreement between two movement disorder specialists according to the Movement Disorders Society (MDS) PD criteria [9]. Both iPD and familial PD cases with their available first-degree relatives were included in the study. Clinicodemographic characteristics of the cohort were uploaded to University College London (UCL) Research Data Capturing Database (Redcap) online secure database and its summary is given in Table 1. There were 21 patients $(8.5 \%, 21 / 246)$ with a family history of $\mathrm{PD}$ and/or tremor, and $31(12.6 \%, 31 / 246)$ patients with the onset of PD before 40 years of age. The male to female ratio was $0.95: 1$. The mean age of PD onset was $55.06 \pm 11.15$ (range 14-77), and the mean age at the last examination was $61.7 \pm 10.3$ (range 28-83). Self-reported nationalities in $72.8 \%$ of the cohort were Kazakh, $20.7 \%$ were Russian, and the remaining nationalities were Uyghur (2.8\%), Tatar (2\%), Korean (1.3\%), and Tajik (0.4\%). Genomic DNAs of age- and gender-matched 200 unrelated control subjects were obtained from the research-ready database of neurologically healthy Kazakhs from the National Center for Biotechnology, Nur-Sultan (NCB).

This study was approved by the Research Ethics Committee of NCB (4/29.08.2017) and the Institute of Neurology 


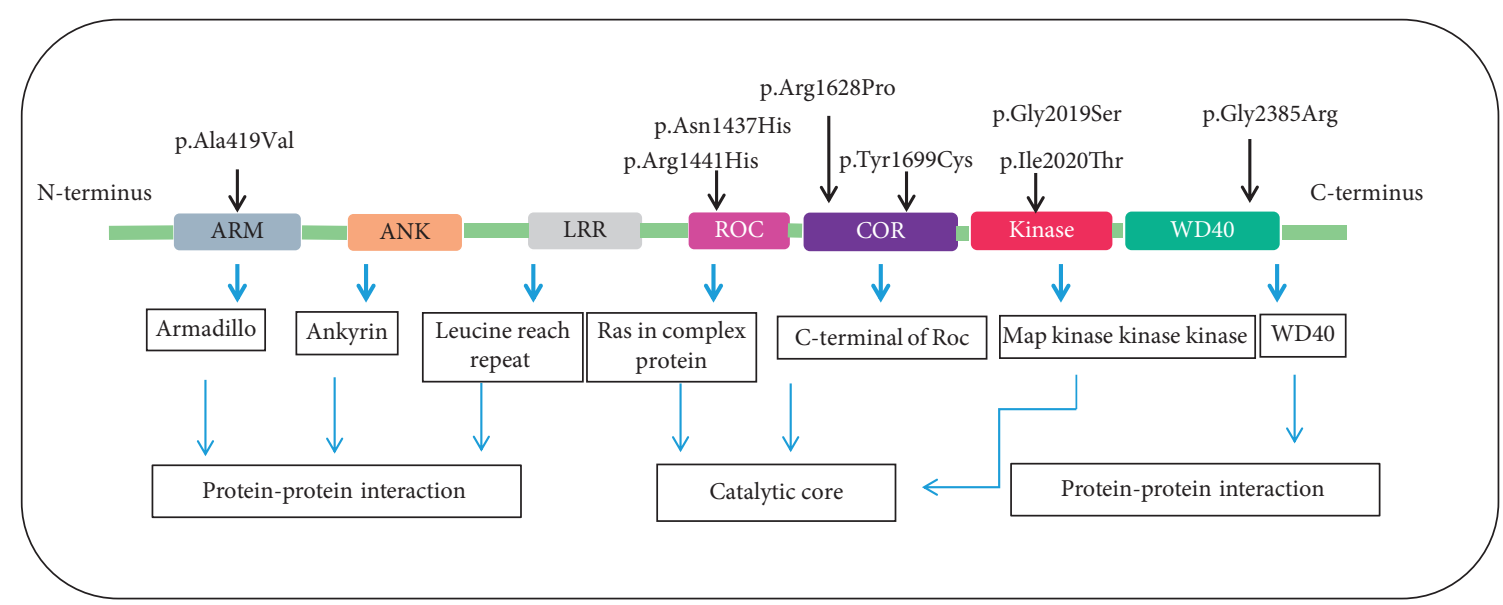

FIGURE 1: LRRK2 protein: functional domain and the localization of 8 variants. ANK-ankyrin repeat; ARM-armadillo; LRR-leucine-rich repeat; ROC-Ras of complex proteins: GTPase; COR-C-terminal of ROC; WD40-WD-40 domain. Pathogenic mutations are highlighted in blue, and East Asian disease-associated variants are highlighted in red.

University College London (IoN UCL) (07/Q0512/26). Written informed consent for participation in the study was obtained from each subject. All personal information was hidden with unique study identifiers.

2.2. Genetic Analysis. Whole venous blood was collected from the subjects at the recruitment centers and sent to $\mathrm{NCB}$ for DNA extraction using the standardized laboratory protocols. DNAs were then shipped to IoN UCL for genetic analysis. At IoN, DNAs were checked for quality and concentrations using NanoDrop Spectrophotometer (Thermo Scientific, Waltham, MA, USA). Samples were uniformly diluted to $25 \mathrm{ng} / \mu \mathrm{l}$, and $25 \mu \mathrm{l}$ volume of DNA from each sample was transferred to $96-$-well plates.

On the basis of the literature review, 8 LRRK2 singlenucleotide polymorphisms (SNPs) of interest were selected for the analysis. Five of them are commonly reported LRRK2 mutations: (c.6055G $>$ A) p.Gly2019Ser (rs34637584), (c.4322G $>$ A) p.Arg1441His (rs34995376), (c.5096A >G) p.Tyr1699Cys (rs35801418), (c.6059T >C) p.Ile2020Thr (rs35870237), and (c.4309A>C) p.Asn1437His (rs74163686); and three of them are the East Asian-specific PD-associated variants: (c.7153G $>$ A) p.Gly2385Arg (rs34778348), (c.1256C $>$ T) p.Ala419Val (rs34594498), and (c.4883G>C) p.Arg1628Pro (rs33949390) (Figure 1). The SNPs and surrounding 50 base-pairs were annotated in Ensembl genome browser (see S1 in the supplementary material for comprehensive analysis). The design of primers, adaptation of assays, and genetic analysis were performed in LGC Genomics, England. No positive and negative controls were available for the selected LRRK2 SNPs. LRRK2 genotyping was done using Kompetitive Allele-Specific Polymerase chain reaction (PCR) genotyping assay (KASP ${ }^{\mathrm{TM}}$, LGC Genomics. Herts, UK), a method that enables biallelic scoring of SNPs and insertion and deletions at specific loci through competitive allele-specific PCR. Genotyping followed the LGC Genomics protocol. SNP viewer Software (version 1.99, Hoddesdon, UK) was used to visualize the genotyping results (https://www.biosearchtech.com/support/tools/genotyping- software/snpviewer). Familial and young-onset PD cases with positive LRRK2 substitutions were sent for exome sequencing (WES) to Macrogen, South Korea. In addition, when LRRK2 mutations were identified in a proband, Sanger sequencing was performed for all available family members. Thus, we enrolled 13 additional living relatives for the p.Gly2385Arg and p.Ala419Val mutations from two families.

2.3. Statistical Analysis. Statistical analysis was performed using IBM SPSPS version 21 (Chicago, USA). Genotype frequency distributions were tested for conformity to Hardy-Weinberg equilibrium (HWE). T-test and chisquared tests were used at the level of significance 0.05 . Odds ratios (OR) were calculated and presented with $95 \%$ confidence interval (CI) values.

\section{Results}

3.1. KASP Coverage. $1.6-3.2 \%$ of samples were uncalled in KASP assay analysis and this was within the expected values [10]. The number of uncalled samples for each LRRK2 SNP is shown in Supplementary Materials (see S2 and S4 for comprehensive analysis).

3.2. SPNs with Negative Findings. The following most pathogenic LRRK2 mutations p.Gly2019Ser, p.Arg1441His, p.Tyr1699Cys, p.Ile2020Thr, and p.Asn1437His were not found in our cohort of PD patients and controls. All of the 246 PD subjects and 200 controls were homozygous for wildtype alleles of these SNPs (Table 2). The allelic frequencies for the aforementioned SNPs were in Hardy-Weinberg equilibrium $(p=1)$.

\subsection{SNPs with Positive Findings}

3.3.1.p.Gly2385Arg (c.7153G>A). Monoallelic p.Gly2385Arg variant (rs34778348) was found in three PD cases (1.2\%, $n=3 / 239)$ and two controls $(1 \%, n=2 / 199)$ (Table 3$)$. The 
TABLE 2: Allele frequency and distribution of the 8 tested LRRK2 variants.

\begin{tabular}{|c|c|c|c|c|c|c|c|c|}
\hline SNP & $\begin{array}{l}\text { Hardy-Weinberg equilibrium } \\
\text { p-value }\end{array}$ & $\begin{array}{l}\text { Number of } \\
\text { samples }\end{array}$ & Allele & $n^{\mathrm{a}}$ & Frequency & Genotype & $n^{\mathrm{b}}$ & Frequency \\
\hline \multirow{6}{*}{ p.Gly2019Ser (c.6055G>A) } & \multirow{4}{*}{1} & \multirow{4}{*}{198 controls } & & & & GG & 198 & 1.00 \\
\hline & & & G & 396 & 1.00 & GA & 0 & 0.00 \\
\hline & & & A & 0 & 0.00 & AA & 0 & 0.00 \\
\hline & & & & 482 & 1.00 & GG & 241 & 1.00 \\
\hline & \multirow[t]{2}{*}{1} & \multirow[t]{2}{*}{$241 \mathrm{PD}$} & G & 0 & 0.00 & GA & 0 & 0.00 \\
\hline & & & A & & & $\mathrm{AA}$ & 0 & 0.00 \\
\hline \multirow{6}{*}{ p.Arg1441His $(c .4322 \mathrm{G}>\mathrm{A})$} & \multirow{4}{*}{1} & \multirow{4}{*}{199 controls } & & & & GG & 199 & 1.00 \\
\hline & & & G & 398 & 1.00 & GA & 0 & 0.00 \\
\hline & & & $\mathrm{A}$ & 0 & 0.00 & AA & 0 & 0.00 \\
\hline & & & & 480 & 1.00 & GG & 240 & 1.00 \\
\hline & \multirow[t]{2}{*}{1} & \multirow[t]{2}{*}{$240 \mathrm{PD}$} & G & 0 & 0.00 & GA & 0 & 0.00 \\
\hline & & & A & & & AA & 0 & 0.00 \\
\hline \multirow{6}{*}{ p.Tyr1699Cys (c.5096A>G) } & \multirow{3}{*}{1} & \multirow{3}{*}{196 controls } & & & & GG & 196 & 1.00 \\
\hline & & & G & 392 & 1.00 & GA & 0 & 0.00 \\
\hline & & & A & 0 & 0.00 & AA & 0 & 0.00 \\
\hline & \multirow{3}{*}{1} & \multirow{3}{*}{$239 \mathrm{PD}$} & & 478 & 1.00 & GG & 239 & 1.00 \\
\hline & & & G & 0 & 0.00 & GA & 0 & 0.00 \\
\hline & & & A & & & AA & 0 & 0.00 \\
\hline \multirow{6}{*}{ p.Ile2020Thr (c.6059T>C) } & \multirow{4}{*}{1} & \multirow{3}{*}{198 controls } & & & & TT & 198 & 1.00 \\
\hline & & & $\mathrm{T}$ & 396 & 1.00 & TC & 0 & 0.00 \\
\hline & & & $\mathrm{C}$ & 0 & 0.00 & $\mathrm{CC}$ & 0 & 0.00 \\
\hline & & \multirow{3}{*}{242 PD } & & 484 & 1.00 & TT & 242 & 1.00 \\
\hline & \multirow[t]{2}{*}{1} & & $\mathrm{~T}$ & 0 & 0.00 & $\mathrm{TC}$ & 0 & 0.00 \\
\hline & & & $\mathrm{C}$ & & & $\mathrm{CC}$ & 0 & 0.00 \\
\hline & & & & & & AA & 198 & 1.00 \\
\hline & 1 & 199 controls & A & 398 & 1.00 & $\mathrm{AC}$ & 0 & 0.00 \\
\hline p. Asn 1437 His $(c .4309 \mathrm{~A}>\mathrm{C})$ & & & $\mathrm{C}$ & 0 & 0.00 & $\mathrm{CC}$ & 0 & 0.00 \\
\hline P.Asm14J/HIS (c.4J09A $>c)$ & & & & 480 & 1.00 & AA & 240 & 1.00 \\
\hline & 1 & $240 \mathrm{PD}$ & A & 0 & 0.00 & $\mathrm{AC}$ & 0 & 0.00 \\
\hline & & & $\mathrm{C}$ & & & $\mathrm{CC}$ & 0 & 0.00 \\
\hline & & & & & & GG & 197 & 0.99 \\
\hline & 0.94 & 199 controls & G & 396 & 0.995 & GA & 2 & 0.01 \\
\hline p.Glv2385Arg $(c .7153 \mathrm{G}>\mathrm{A})$ & & & A & 2 & 0.005 & AA & 0 & 0.00 \\
\hline p.Glyz38sArg (c./153G>A) & & & & & & GG & 236 & 0.99 \\
\hline & 0.92 & 239 PD & G & 475 & 0.993 & GA & 3 & 0.01 \\
\hline & & & A & 3 & 0.007 & $\mathrm{AA}$ & 0 & 0.00 \\
\hline & & & & & & $\mathrm{CC}$ & 194 & 0.98 \\
\hline & 0.85 & 199 controls & $\mathrm{C}$ & 393 & 0.988 & CT & 5 & 0.02 \\
\hline & & & $\mathrm{T}$ & 5 & 0.012 & TT & 0 & 0.00 \\
\hline p.Ala419Val (c.1256C>1) & & & & & 0.98 & $\mathrm{CC}$ & 233 & 0.97 \\
\hline & 0.004 & $242 \mathrm{PD}$ & $\mathrm{C}$ & 474 & 0.02 & CT & 8 & 0.04 \\
\hline & & & $\mathrm{T}$ & 10 & & TT & 1 & 0.00 \\
\hline & & & & & & GG & 197 & 0.99 \\
\hline & 0.94 & 199 controls & G & 396 & 0.995 & GT & 2 & 0.01 \\
\hline & & & $\mathrm{C}$ & 2 & 0.005 & TT & 0 & 0.00 \\
\hline p.Arg1628Pro (c.4883G>C) & & $236 \mathrm{PD}$ & & & & GG & 236 & 1.00 \\
\hline & 1 & & G & 472 & 1.00 & GT & 0 & 0.00 \\
\hline & & & $\mathrm{C}$ & 0 & 0.00 & TT & 0 & 0.00 \\
\hline
\end{tabular}

n1-number of alleles, $n 2-$ number of genotypes, PD-Parkinson's disease, HWE-Hardy-Weinberg equilibrium, and NA-not applicable.

TABLE 3: p.Gly2385Arg-positive PD patients and their characteristics.

\begin{tabular}{lcccccc}
\hline & $\begin{array}{c}\text { Number (246-7 } \\
\text { uncalled =239) }\end{array}$ & $\begin{array}{c}\text { Mean age at } \\
\text { examination }\end{array}$ & $\begin{array}{c}\text { Mean age of } \\
\text { onset }\end{array}$ & $\begin{array}{c}\text { Mean disease } \\
\text { duration }\end{array}$ & $\begin{array}{c}\text { Family } \\
\text { history }\end{array}$ & $\begin{array}{c}\text { Mean HY stage } \\
\text { off }\end{array}$ \\
\hline Carriers & 3 & $58.6 \pm 13.4$ & $55 \pm 12.1$ & $4 \pm 0.8$ & 1 & $2 \pm 0.8$ \\
Noncarriers & 236 & $61.7 \pm 10.3$ & $55 \pm 11.1$ & $6.8 \pm 4.7$ & 20 & $2.3 \pm 1.5$ \\
$p$ value & & $\mathbf{0 . 7 7}$ & $\mathbf{0 . 9 9}$ & $\mathbf{0 . 0 1}$ & $\mathbf{0 . 5 6}$ \\
\hline
\end{tabular}




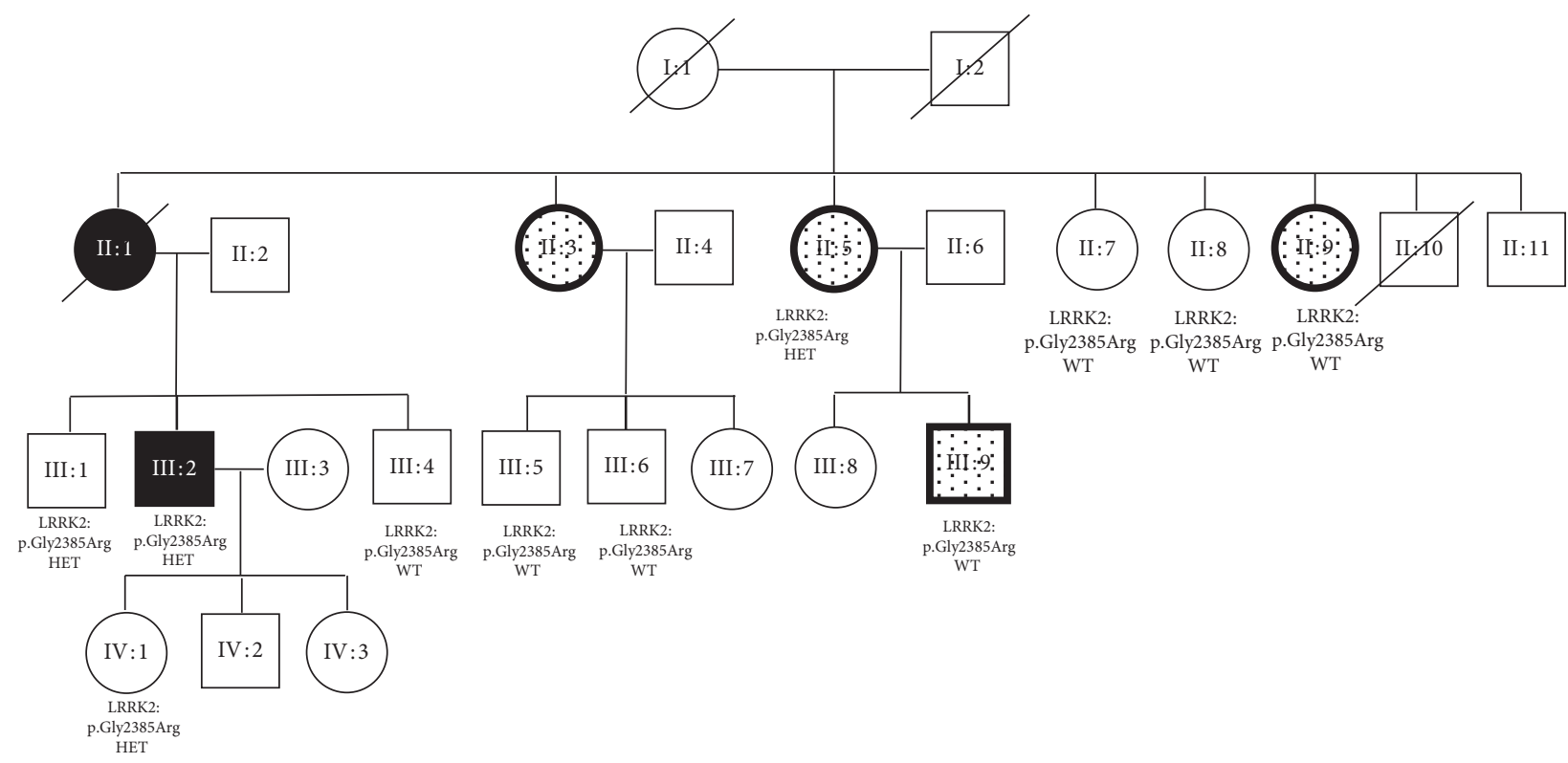

FIGURe 2: Familial case with p.Gly2385Arg variant. III:2 Proband 40 years old, PD onset at 38 years. II:1 Affected mother of the proband. PD onset at 55 years. Died at 58 years. Levodopa responsive PD. II:3 affected maternal aunt. 10 years' history of unilateral right-hand tremor at rest and action. II:5 Affected maternal aunt, 54 years old. 10 years' history of positional unilateral tremor. III:9 son of II:5. Right-hand positional tremor. II:9 Affected maternal aunt, 4-5 years' history of right-hand positional tremor.

first positive case was a young Kazakh male with an autosomal dominant family history of PD. He developed PD at the age of 38 years, and the onset symptoms were depression, anxiety, hyposmia, and left-hand tremor. He had an affected mother, who had developed PD at the age of 55 years and deceased at the age of 58 years. Interestingly, his mother had three female siblings with upper-limb tremor but no signs of bradykinesia (Figure 2). He had fast progression in the disease course and in two years from the disease onset developed difficulty in rising up from a chair, freezing episodes, urinary frequency, and gait abnormalities. His offstage MDS UPDRS motor scale score was 79 with Hoehn-Yahr stage 3. There was a good response to levodopa. WES in the proband did not reveal any other known PD genes. p.Gly2385Arg variant was tested in six of his healthy relatives and in those with tremor $(n=4)$ by Sanger sequencing. The variant was present in one of the two unaffected siblings of the proband, unaffected 20 -year-old daughter of the proband, and in only one out of the four relatives with tremor (Figure 2 ).

The second PD case was a 71-year-old Kazakh female with sporadic PD onset at the age of 66 years. She had a mild and slowly progressive disease course. Her off-stage MDS UPDRS motor score was 16 and Hoehn-Yahr stage 1. Dopamine agonists effectively controlled her motor symptoms.

The third PD case was a 65-year-old Kazakh female with sporadic PD with the onset at the age of 61 years. She had also a mild disease course and was not on levodopa. Her off-stage MDS UPDRS motor score was 14 and Hoehn-Yahr stage 2.

p.Gly2385Arg positive healthy controls were 50 -year-old and 54-year-old male and female subjects. The allelic and genotypic frequencies for p.Gly2385Arg were in
Hardy-Weinberg equilibrium $(p=0.9)$ and did not statistically differ between cases and controls (OR 1.25, 95\% C.I.: 0.2071-7.5688, $p=0.8$ ) (Tables 2 and 4).

3.3.2. p.Ala419Val (c.1256C>T). LRRK2 p.Ala419Val variant (rs34594498) was positive in 9 PD cases $(3.7 \%, n=9 / 242)$ and 5 controls $(2.5 \%, n=5 / 199)$, giving the OR of $1.5(95 \%$ C.I.: $0.4941-4.5463, p=0.4$ ) (Table 4). WES in the probands with young-onset and familial PD did not reveal any other known PD genes. One positive case had homozygous substitution in c.1256C $>\mathrm{T}(\mathrm{T} / \mathrm{T})$. This was a 52 -year-old Kazakh patient with the onset of sporadic PD at the age of 48 years. The patient expressed akinetic-rigid PD with a good response to levodopa but early and severe motor complications. He reached HY stage 3 in four years from the onset of motor symptoms. Two unaffected children of the proband were heterozygous for LRRK2 c.1256C $>\mathrm{T}$ substitution, whereas one unaffected sibling of the proband did not have LRRK2 c.1256C>T substitution on Sanger sequencing segregation analysis (Figure 3) (see Figure S3 in the supplementary material for comprehensive image analysis).

Five out of the 9 LRRK2 2 .Ala419Val carriers developed PD before the age of 50 years, the youngest manifestation being at the age of 26 years. The mean age at onset for the p.Ala419Val carriers was $48.3 \pm 12.6$ (range 26-69) and this did not significantly differ from the noncarriers $(48.3 \pm 12.6$ $\mathrm{v} 54.7 \pm 12.3, p=0.19)$. The mean age at examination was $57.4 \pm 12.9$ (range $32-82$ ), and mean disease duration was $9.1 \pm 6.1$ (range 2-20) (Table 5). The mean HYS score for the positive cases was $2.5 \pm 0.5$.

Interestingly, self-reported nationalities in three out of the nine positive cases were Russian, one case was half Kazakh and half Russian, and the remaining 5 cases were 
TABLE 4: The allelic frequency and odds ratios for the positive LRRK2 Asian disease-associated variants.

\begin{tabular}{|c|c|c|c|c|c|c|}
\hline \multirow{2}{*}{ SNP } & \multirow{2}{*}{ Nucleotide change } & \multirow{2}{*}{ Amino acid change } & \multicolumn{2}{|l|}{ MAF } & \multirow{2}{*}{ Or $(95 \% \mathrm{CI})$} & \multirow{2}{*}{$p$ value } \\
\hline & & & $\mathrm{PD}\left(n=239^{\mathrm{a}}, 242^{\mathrm{b}}, 236^{\mathrm{c}}\right)$ & Controls $(n=199)$ & & \\
\hline rs34778348 & c. $7153 \mathrm{G}>\mathrm{A}$ & p.Gly2385Arg ${ }^{a}$ & $0.007(\mathrm{~A})$ & $0.005(\mathrm{~A})$ & $1.25(0.2071-7.5688)$ & 0.8 \\
\hline rs34594498 & c. $1256 \mathrm{C}>\mathrm{T}$ & p.Ala419Val & $0.02(\mathrm{~T})$ & $0.012(\mathrm{~T})$ & $1.5(0.4941-4.5463)$ & 0.4 \\
\hline rs33949390 & c. $4883 \mathrm{G}>\mathrm{C}$ & p.Arg1628Pro ${ }^{c}$ & $0.0(\mathrm{C})$ & $0.005(\mathrm{C})$ & NA & NA \\
\hline
\end{tabular}

MAF-minor allele frequency, NA-not applicable, OR-odds ratio, and PD-Parkinson's disease.

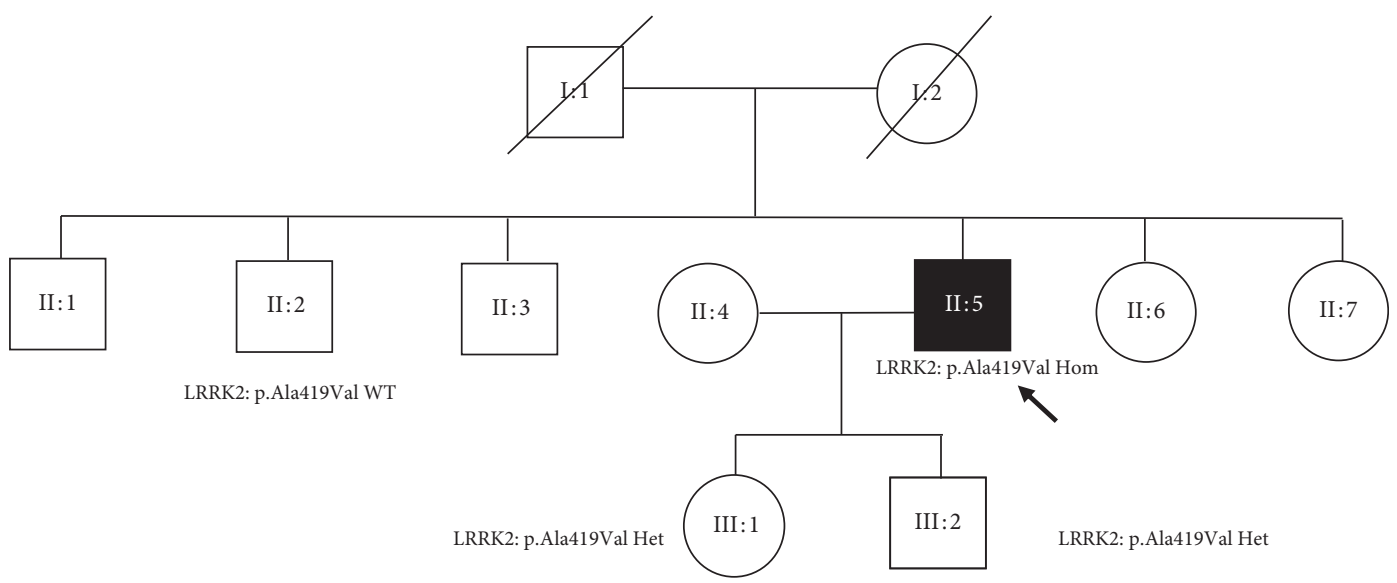

FIgURE 3: Homozygous p.Ala419Val proband and his family tree.

TABLE 5: p.Ala419Val-positive PD patients and their characteristics.

\begin{tabular}{lcccccc}
\hline & $\begin{array}{c}\text { Number 246- } \\
\text { 4uncalled }=242\end{array}$ & $\begin{array}{c}\text { Mean age at } \\
\text { examination }\end{array}$ & $\begin{array}{c}\text { Mean age of } \\
\text { onset }\end{array}$ & $\begin{array}{c}\text { Mean disease } \\
\text { duration }\end{array}$ & $\begin{array}{c}\text { Family } \\
\text { history }\end{array}$ & $\begin{array}{c}\text { Mean HY stage } \\
\text { off }\end{array}$ \\
\hline Carriers & 9 & $57.4 \pm 12.9$ & $48.3 \pm 12.6$ & $9.1 \pm 6.1$ & 2 & $2.5 \pm 0.5$ \\
Noncarriers & 233 & $61.6 \pm 10.4$ & $54.7 \pm 12.3$ & $6.8 \pm 7$ & 19 & $2.2 \pm 0.7$ \\
$P$ value & & $\mathbf{0 . 3 8}$ & $\mathbf{0 . 1 9}$ & $\mathbf{0 . 3}$ & $\mathbf{0 . 0 2}$ \\
\hline
\end{tabular}

HY-Hoehn-Yahr.

Kazakhs. Two of the Russian patients had an autosomal dominant history of PD with onset after the age of 50 years. All of the LRRK2 p.Ala419Val-positive cases had a good response to levodopa. The allele frequencies for LRRK2 p.Ala419Val in PD cases deviated from Hardy-Weinberg equilibrium $(p=0.004)$ (Table 2$)$.

3.3.3. p.Arg1628Pro (c.4883G>C). PD cases were negative for p.Arg1628Pro (rs33949390) variant, whereas two control subjects were found to be positive $(1 \%, n=2 / 199)$. The variant was in Hardy-Weinberg equilibrium $(p=0.9)$ in controls.

\section{Discussion}

This study screened cohorts of PD patients and controls from Kazakhstan for five LRRK2 mutations and three Asian disease-associated variants. To date, over 80 LRRK2 disease-causing and disease-associated variants have been described in literature since the gene was discovered in 2004. However, only eight of them have been acknowledged as PD-causing mutations including p.Gly2019Ser, p.Arg1441His, p. Arg1441Cys, p.Arg1441Gly, p.Tyr1699Cys, p.Ile2020Thr, p. Asn1437His, and p. Ile2012Thr. All of these mutations affect the catalytic core of the LRRK2 enzyme [11]. Among these mutations, p.Gly2019Ser is the most common followed by the substitution of arginine (Arg) by glycine (Gly), cysteine (Cys), or histidine (His) in the position 1441 of LRRK2 gene [11]. p.Gly2019Ser mutation has a global prevalence of $1 \%$ in patients with $\mathrm{PDD}$ and around $4 \%$ in familial PD. It is noteworthy that p.Gly2019Ser has been predominantly reported in the North African population where it is responsible for $30-42 \%$ of familial and $30-34 \%$ of sporadic PD cases. Its prevalence shows high figures in Ashkenazi Jews (28\% of familial PD and 10\% in iPD) and among European as well as North American populations (6\% and 3\%, respectively) [12]. Conversely, p.Gly2019Ser mutation has not been reported in Asians $(<0.1 \%)[13,14]$. p.Gly2019Ser was reported in Russian PD cohorts (\%), possibly in subjects of Ashkenazi Jewish origin [15].

The currently known most deleterious LRRK2 mutations associated with PD were not found in our cohort. The absence of these mutations in our cohort is similar to other Asian studies [6] This is probably due to the founder effects of these mutations, which seem to be specific to Western populations. 
TABLE 6: Studies investigating LRRK2 p.Gly2385Arg variant in Asian populations.

\begin{tabular}{|c|c|c|c|c|c|}
\hline & Cases & Controls & Ethnicity & OR & MAF for PD patients \\
\hline $\begin{array}{l}\text { Funayama et al., } \\
2007[13]\end{array}$ & $\begin{array}{c}448 / 52(11.6 \%)(2 \\
\text { homozygous cases) }\end{array}$ & $\begin{array}{l}457 / 22 \\
(4.8 \%)\end{array}$ & Japanese & $\begin{array}{c}\text { OR for the frequency of A allele } \\
2.63,95 \% \text { CI: } 1.56-4.35 \\
p=1.24 \times 10^{-4}\end{array}$ & 0.06 \\
\hline $\begin{array}{l}\text { Di Fonzo at al., } \\
2006 \text { [6] }\end{array}$ & $608 / 61(10 \%)$ & $\begin{array}{l}373 / 18 \\
(4.8 \%)\end{array}$ & $\begin{array}{c}\text { Han Chinese from } \\
\text { Taiwan }\end{array}$ & $\begin{array}{c}\mathrm{OR}=2.24,95 \% \mathrm{CI}: 1.29-3.88 \\
p=0.004\end{array}$ & 0.05 \\
\hline $\begin{array}{l}\text { Fung et al., } 2006 \\
{[17]}\end{array}$ & $305 / 27(9 \%)$ & $\begin{array}{l}176 / 1 \\
(0.5 \%)\end{array}$ & $\begin{array}{c}\text { Han Chinese from } \\
\text { Taiwan }\end{array}$ & $\begin{array}{c}16.99,95 \% \text { CI: } 2.29 \text { to } 126.21 \\
p=0.0002\end{array}$ & $\begin{array}{c}0.4 \text { No positive cases with } \\
\text { FH }\end{array}$ \\
\hline $\begin{array}{l}\text { An et al., } 2008 \\
{[21]}\end{array}$ & $\begin{array}{c}600 / 71 \text { (1 } \\
\text { homozygous) (11.9\%) }\end{array}$ & $\begin{array}{l}334 / 11 \\
(3.3 \%)\end{array}$ & Han Chinese & $\begin{array}{c}\text { OR } 3.9,95 \% \mathrm{CI}=2.1-7.5 \\
p<0.01\end{array}$ & 0.06 \\
\hline $\begin{array}{l}\text { Tan et al., } 2007 \\
{[18]}\end{array}$ & $\begin{array}{l}494 / 37(7.27 \%)(1 \\
\text { homozygous) }\end{array}$ & $\begin{array}{c}495 / 18 \\
(3.64 \%)\end{array}$ & Ethnic Chinese & $\begin{array}{c}\text { OR 2.1, 95\% CI: } 1.1-3.9 \\
p=0.014\end{array}$ & $\begin{array}{l}\text { PAR of } 4 \% \text { for the } \\
\text { Gly2385Arg heterozygous } \\
\text { genotype. }\end{array}$ \\
\hline $\begin{array}{l}\text { Tan et al., } 2007 \\
{[8]}\end{array}$ & 166/2 (Malays) & $\begin{array}{c}306 / 2 \\
\text { (Malays) }\end{array}$ & $\begin{array}{c}\text { Malay 98/173, } \\
\text { Indian ethnicity } \\
66 / 133\end{array}$ & OR $2.83,95 \%$ CI $0.40,20.2, p \_0.3$ & 0.003 for Malays \\
\hline $\begin{array}{l}\text { Farrer et al., } \\
2007 \text { [16] }\end{array}$ & $410 / 34$ & $\begin{array}{l}335 / 13 \\
(3.9 \%)\end{array}$ & Ethnic Chinese & $\begin{array}{c}\text { OR } 2.2495 \% \text { CI } 1.16-4.32, \\
p<0.014\end{array}$ & $\begin{array}{c}\text { MAF } 0.08 \\
23.1 \%(n=6 / 26) \text { of patients } \\
\text { with familial parkinsonism. }\end{array}$ \\
\hline $\begin{array}{l}\text { Ross et al., } 2011 \\
{[23]}\end{array}$ & $\begin{array}{c}1,376 \\
\text { Japan } \\
\text { PD: } 173 \\
\text { Korea } \\
\text { |PD: } 844 \\
\text { Taiwan } \\
\text { PD: } 369\end{array}$ & $\begin{array}{l}962 \\
\text { Control: } 75 \\
\text { Control: } \\
587 \\
\text { Control: } \\
300\end{array}$ & $\begin{array}{l}\text { Japan, Korea, } \\
\text { Taiwan }\end{array}$ & $\begin{array}{c}\text { OR: } 1.73,95 \% \text { CI: } 1.20-2.49 \\
\quad p=0.0026\end{array}$ & MAF $3.3 \%$ \\
\hline $\begin{array}{l}\text { Mata et al., } 2005 \\
{[20]}\end{array}$ & $\begin{array}{l}100 \text { probands with } \\
\text { PD FH/2 cases }\end{array}$ & & Taiwan & 1 family with 2 members & \\
\hline $\begin{array}{l}\text { Zabetian et al., } \\
2009[24]\end{array}$ & $601 / 69(11.5 \%)$ & $\begin{array}{c}1628 / 101 \\
(6.2 \%)\end{array}$ & Japanese & $\begin{array}{c}\text { OR, } 1.83 ; 95 \% \text { CI: } 1.31-2.54 \\
\quad p=3.3 \times 10^{-4}\end{array}$ & \\
\hline $\begin{array}{l}\text { Gapalai et al., } \\
2015 \text { [14] }\end{array}$ & 695 & 507 & Malaysian & OR $2.22(p=0.019)$ & $\mathrm{MAF}=0.026$ \\
\hline
\end{tabular}

OR-odds ratio, MAF-minor allele frequency, PAR-population attributable risk, and FH-family history.

4.1. p.Gly2385Arg. LRRK2 p.Gly2385Arg substitution is located in the WD-40 domain, a toroidal beta-propeller structure responsible for protein-protein interactions [16]. There have been 5 independent case-control studies reporting this variant $[6,13,16-18]$ and 14 studies screening their cohorts for p.Gly2385Arg $[14,19]$.

Originally, p.Gly2385Arg variant was identified in a small Taiwanese PD family, in a proband and his affected father [20]. Later, a number of studies in Chinese, Taiwanese, Korean, and Japanese populations have reported p.Gly2385Arg variant significantly more among $\mathrm{PD}$ patients than controls, with minor allele frequency (MAF) up to 0.4 in patients (Table 6). Thus, p.Gly2385Arg variant was attributed to a risk factor for sporadic and familial PD. The population attributable risk for p.Gly2385Arg in Han-Chinese ethnicity was estimated to be around $4 \%$ [18], and the variant probably originated around 4800 years ago from one ancestor [16]. p.Gly2385Arg variant had a tendency for equal distribution across genders and age groups [6]. Regarding the clinical presentation, p.Gly2385Arg carriers expressed typical PD and homozygous cases were not clinically different from heterozygotes and non-carriers [13]. This variant seems not to influence the age of PD onset, as the mean ages of onset in p.Gly2385Arg carriers and non-carriers have not been consistently reported to significantly differ between these groups
$[6,13,17]$. Reports on the association of p.Gly2385Arg carrier status with a family history of PD have also been inconsistent $[16,17]$.

In regards to non-Chinese populations, p.Gly2385Arg was found in $1.2 \%(2 / 166)$ of PD patients and $0.6 \%(2 / 306)$ of controls in Malay/Indian ethnicity from Singapore [8] The frequency of p.Gly2385Arg in cases and controls was not significantly different in this Singaporean study, and considerably lower than the frequency of $8-10 \%$ reported in Chinese PD subjects $[6,8]$. A recent study on Malaysian PD subjects has found a significant association between p.Gly2385Arg and increased risk of PD [14] The variant was absent in 405 Iranian subjects [22] and positive in only one individual of Northern European origin among 14,002 screened Caucasian subjects [25].

Evidence from functional studies suggests that p.Gly2385Arg substitution leads to the replacement of hydrophobic glycine with the hydrophilic arginine and increases the net positive charge on the 40WD domain of LRRK2. Both LRRK2 proteins with wild-type and p.Gly2385Arg variant localized to the cytoplasm forming aggregates, but the intensity of apoptosis is higher in p.Gly2385Arg variant under oxidative stress conditions [18].

The frequency of p.Gly2385Arg variant in our study (1.2\% patients and $1 \%$ controls) was almost similar to non- 
TABLE 7: Studies investigating LRRK2 p.Ala419Val variant in Asian populations.

\begin{tabular}{|c|c|c|c|c|c|}
\hline & Cases & Controls & Ethnicity & OR & $\begin{array}{l}\text { MAF for patients/ } \\
\text { controls }\end{array}$ \\
\hline $\begin{array}{l}\text { Di Fonzo et al., } 2006 \\
\text { [6] }\end{array}$ & $582 / 10$ & $341 / 3$ & Han Chinese from Taiwan & $1.95(0.53-7.15), p>0.05$ & $0.008 / 0.004$ \\
\hline $\begin{array}{l}\text { Nuytemans et al., } \\
2009 \text { [27] }\end{array}$ & $620 / 1$ & $540 / 0$ & Belgian & $p>0.05$ & \\
\hline $\begin{array}{l}\text { Jasinska-Myga, } 2010 \\
\text { [12] }\end{array}$ & $165 / 0$ & $364 / 0$ & Arab-Berber ethnicity & $\mathrm{n} / \mathrm{a}$ & \\
\hline Tan et al., 2010 [28] & $250 / 0$ & $250 / 0$ & Han Chinese & $\mathrm{n} / \mathrm{a}$ & \\
\hline \multirow[t]{4}{*}{ Ross et al., 2011 [23] } & 1,376 & 962 & Japan, Korea, Taiwan & $\begin{array}{c}\text { OR: } 2.27,95 \% \text { CI: } 1.35-3.83 \text {, } \\
p=0.0011\end{array}$ & \\
\hline & $\begin{array}{l}\text { Japan PD: } \\
\quad 173\end{array}$ & $\begin{array}{l}\text { Control: } \\
75\end{array}$ & & Japan: OR 1.26 (0.38 to 4.22$)$ & \\
\hline & $\begin{array}{l}\text { Korea PD: } \\
\quad 844\end{array}$ & $\begin{array}{l}\text { Control: } \\
587\end{array}$ & & Korea: OR 2.21 (1.2 to 4.06$)$ & \\
\hline & $\begin{array}{c}\text { Taiwan PD: } \\
369\end{array}$ & $\begin{array}{l}\text { Control: } \\
300\end{array}$ & & $\begin{array}{c}\text { Taiwan: OR } 7.51 \text { (0.95 to } \\
59.6)\end{array}$ & \\
\hline Li et al., 2012 [29] & $729 / 22$ & $585 / 4$ & Han Chinese & $\begin{array}{c}\text { OR, } 4.14 ; 95 \% \mathrm{CI}: \\
1.53-12.74\end{array}$ & 0.015 \\
\hline Wu et al., 2012 [30] & $1517 / 13$ & $1487 / 13$ & $\begin{array}{c}\text { Han Chinese from China and } \\
\text { Singapore Taiwanese }\end{array}$ & $0.98(0.45$ to 2.18$)$ & 0.004 \\
\hline $\begin{array}{l}\text { Gopalai et al., } 2013 \\
\text { [31] }\end{array}$ & $404 / 1$ & $424 / 3$ & $\begin{array}{c}\text { Chinese }(223 / 236), \text { Malay }(122 / 110) \text {, } \\
\text { and Indian }(59 / 78)\end{array}$ & $\begin{array}{c}0.35,95 \% \text { CI: } 0.01 \text { to } 3.79 \\
p=0.624\end{array}$ & $\begin{array}{c}0.002 \text { cases } \\
0.004 \text { Controls }\end{array}$ \\
\hline $\begin{array}{l}\text { Heckman et al., } 2013 \\
{[32]}\end{array}$ & $369 / 10$ & $300 / 1$ & Taiwan, South Korea, Japan & OR 8.33 (1.06-65.43) & $\begin{array}{c}\text { Taiwanese } 0.013 \\
\text { Japanese }-0.026 \\
\text { South Korea } 0.029\end{array}$ \\
\hline $\begin{array}{l}\text { Wu-Chou et al., } 2013 \\
\text { [33] }\end{array}$ & $626 / 0$ & $473 / 0$ & Han Chinese from Taiwan & $\mathrm{n} / \mathrm{a}$ & \\
\hline Li et al., 2015 [26] & $500 / 18$ & $574 / 9$ & Chinese & $\begin{array}{c}\text { OR 2.57, 95\% CI: } 1.13-5.86 \\
p=0.025\end{array}$ & 0.018 \\
\hline
\end{tabular}

OR-odds ratio and MAF-minor allele frequency.

Chinese Singaporean subjects. If MAF for Gly2385Arg in Chinese and Japanese PD populations was between 0.05 and 0.4 (Table 6), MAF in our study was 0.007 . This might suggest that p.Gly2385Arg could be found in non-Chinese Asians but in considerably less proportion. Due to a small amount of non-Chinese subjects screened for p.Gly2385Arg and its equal distribution between patients and healthy controls, currently, it is difficult to ascertain the role of this LRRK2 variant in the risk of PD among Central Asian populations. Contemporary data suggest that p.Gly2385Arg could be a risk factor for PD only in selected Asian races.

On the other hand, among three patients positive to p.Gly2385Arg in our study, we had an interesting familial PD case, where proband and his deceased mother had PD, whereas maternal siblings and one maternal cousin of the proband had unilateral asymmetric UL tremor. Although all other known PD genes have been excluded by WES in the proband, p.Gly2385Arg did not completely segregate in the family, being positive in some unaffected family members and negative in some affected (Figure 2). To date, the variant has been shown to segregate with PD in only one small Taiwanese family with affected proband, affected father of the proband, and unaffected sibling. We showed the segregation of p.Gly2385Arg, although incomplete, in a larger family presenting not only with PD but tremor. The incomplete segregation in our family could be due to reduced penetrance or other unknown genetic factors.
4.2. p.Ala419Val. There have been nine reports describing p.Ala419Val variant [26]. The variant resides in the LRRK2 Armadillo domain and is predicted deleterious by online prediction tools with high conservation in the vertebrates [26].

Initially, the association between this variant and PD was described by Ross et al. [23] where p.Ala419Val was tested in 2,338 Asian subjects from Japan, Korea, and Taiwan (1,376 PD cases and 962) in a large-scale multicenter study. The study results revealed the OR of 2.27 (95\% CI: 1.35-3.83, $p=0.0011)$. Several studies before and after the reported association of p.Ala419Val with PD have found either no carriers of this variant in large cohorts of PD patients and controls or insignificant OR (Table 7), thus considering the variant as putatively nonpathogenic population-specific SNP.

The MAF for p.Ala419Val in PD patients has been $0.002-0.018$ in Chinese, and 0.026-0.029 in Japanese and Korean populations in studies reporting positive association $[23,31]$. Interestingly, the replication studies in the Chinese and Taiwanese ethnicities have yielded inconsistent results. While p.Ala419Val was negative or positive with insignificant OR in some studies, several studies and their metaanalysis reported a significant association between this variant and predominantly early-onset PD (Table 7, [26]). This has been explained by possible natural sampling variation and population heterogeneity [30] on the one hand. 
On the other hand, $\mathrm{Li}$ et al. [26] argued that the discrepancy is likely to result from different mean ages at onset (AAO) of PD patients in these studies. Thus, while the mean AAO in p.Ala419Val-positive reports on Chinese ethnicity was $<55$ years $[23,26,29]$, negative reports on the same population had AAO above 60 years [28, 30, 31, 33]. Provided the fact that p.Ala419Val might have a strong association with earlyonset Chinese PD, the likelihood of yielding positive findings could be higher in young-onset PD cohorts.

The MAF for p.Ala419Val in PD patients in our study was 0.02 , which is higher than in Chinese and Taiwanese populations and closer to Japanese and Korean (Table 7). Taking into account the young mean AAO in our Kazakhstani PD cohort $(55.06 \pm 11.15)$ and reference to $\mathrm{Li}$ et al. [26], one might explain the high MAF for p.Ala419Val. Moreover, the AAO in p.Ala419Val-positive PD patients was remarkably young $(48.3 \pm 12.6)$ in our study. However, the high frequency (MAF 0.012) of p.Ala419Val in healthy Kazakhstani controls, who also had a mean age of below 55 years, and insignificant OR do not allow us to ascertain the pathogenicity of p.Ala419Val in Kazakhstani PD.

We have found a previously unreported homozygous carrier of p.Ala419Val variant with PD onset before 50 years and relatively aggressive disease course. If this LRRK2 variant is nonpathogenic and not rare in our population, the likelihood of p.Ala419Val homozygous carriers would increase and this might result in the HWE deviation.

p.Ala419Val variant seems to be present not only in Kazakhs but also in self-reported Russian patients with lateonset or familial PD. Considering the reported specificity of p.Ala419Val to Asian populations, we could speculate that these self-reported Russian subjects in our study could have a mixed ethnic background, particularly with Tatars, an Asian population with some Russian phenotypic features. Alternatively, the variant could also be present in the Russian population.

4.3. p.Arg1628Pro. Regarding p.Arg1628Pro, data from a meta-analysis, including 19 studies with a total of 9,927 PD patients and 8,602 controls, suggest that the variant is significantly associated with the risk of PD in East Asian populations [34]. We failed to find this variant in our PD patients but it was present in controls. This might suggest that p.Arg1628Pro could be a common benign polymorphism in Kazakhstani population.

We have to acknowledge the limitations in our study due to the relatively small sample size, the nonhomogeneous ethnic composition of the PD cohort, as only $72.8 \%$ of the PD cohort were Kazakhs. In addition, controls were not perfectly matched to cases by age, gender, and ethnicity.

\section{Conclusions}

The negative findings on common LRRK2 PD causing mutations, and the presence of LRRK2 Asian-specific variants in our PD patients, although at insignificant level compared with controls, suggest that further large-cohort genetic studies are required in Central Asia to ascertain the pathogenicity of LRRK2 Asian-specific variants in the Central Asian PD population.

\section{Data Availability}

VCF files from exome sequencing used to support the findings of this study are available from the corresponding author upon request.

\section{Conflicts of Interest}

The authors have no conflicts of interest.

\section{Acknowledgments}

Cases were collected as part of the SYNaPS Study Group collaboration funded by The Wellcome Trust and Strategic Award (Synaptopathies) Funding (WT093205MA and WT104033AIA). This research was conducted as part of the Queen Square Genomics group at University College London, supported by the National Institute for Health Research University College London Hospitals Biomedical Research Centre. This research was funded by the Medical Research Council (MRC) (MR/S01165X/1, MR/S005021/1, and G0601943).

\section{Supplementary Materials}

S1: the 8 LRRK2 SNPs and surrounding 50 base-pairs annotated in Ensembl genome browser S2: calculations of allelic and genotypic frequencies, odds ratios, and HardyWeinberg equilibrium S3: chromatogram for Ala419Val homozygous variant with family segregation S4: the results of KASP analysis. (Supplementary Materials)

\section{References}

[1] A. H. V. Schapira, "The importance of LRRK2 mutations in Parkinson disease," Archives of Neurology, vol. 63, no. 9, pp. 1225-1228, 2006.

[2] I. F. Mata, W. J. Wedemeyer, M. J. Farrer, J. P. Taylor, and K. A. Gallo, "LRRK2 in Parkinson's disease: protein domains and functional insights," Trends in Neurosciences, vol. 29, no. 5, pp. 286-293, 2006.

[3] A. B. West, D. J. Moore, S. Biskup et al., "From the cover: Parkinson's disease-associated mutations in leucine-rich repeat kinase 2 augment kinase activity," Proceedings of the National Academy of Sciences, vol. 102, no. 46, pp. 1684216847, 2005.

[4] B. I. Giasson, J. P. Covy, N. M. Bonini et al., "Biochemical and pathological characterization of Lrrk2," Annals of Neurology, vol. 59, no. 2, pp. 315-322, 2006.

[5] L. Parisiadou and H. Cai, "LRRK2 function on actin and microtubule dynamics in Parkinson's disease," Communicative \& Integrative Biology, vol. 3, no. 5, pp. 396-400, 2010.

[6] A. Di Fonzo, Y.-H. Wu-Chou, C.-S. Lu et al., "A common missense variant in the LRRK2 gene, Gly2385Arg, associated with Parkinson's disease risk in Taiwan," Neurogenetics, vol. 7, no. 3, pp. 133-138, 2006.

[7] C. P. Zabetian, C. M. Hutter, D. Yearout et al., "LRRK2 G2019S in families with Parkinson disease who originated from Europe and the Middle East: evidence of two distinct 
founding events beginning two millennia ago," The American Journal of Human Genetics, vol. 79, no. 4, pp. 752-758, 2006.

[8] E.-K. Tan, Y. Zhao, L. Tan et al., "Analysis ofLRRK2 Gly2385Arg genetic variant in non-Chinese Asians," Movement Disorders, vol. 22, no. 12, pp. 1816-1818, 2007.

[9] R. B. Postuma, D. Berg, M. Stern et al., "MDS clinical diagnostic criteria for Parkinson's disease," Movement Disorders, vol. 30, no. 12, pp. 1591-1601, 2015.

[10] C. Broccanello, F. A. ChiodiC, J. M. McGrath, L. Panella, and P. Stevanato, "Comparison of three PCR-based assays for SNP genotyping in plants," Plant Methods, vol. 14, pp. 1-8, 2018.

[11] M. L. Chen and R. M. Wu, "LRRK 2 gene mutations in the pathophysiology of the ROCO domain and therapeutic targets for Parkinson's disease," Journal of Biomedical Science, vol. 25, p. 52, 2018.

[12] B. Jasinska-Myga, J. Kachergus, C. Vilariño-Güell et al., "Comprehensive sequencing of the LRRK2 gene in patients with familial Parkinson's disease from North Africa," Movement Disorders, vol. 25, no. 13, pp. 2052-2058, 2010.

[13] M. Funayama, Y. Li, H. Tomiyama et al., "Leucine-rich repeat kinase 2 G2385R variant is a risk factor for Parkinson disease in Asian population," Neuroreport, vol. 18, no. 3, pp. 273-275, 2007.

[14] A. A. Gopalai, S. Y. Lim, J. Y. Chua et al., "LRRK2 G2385R and R1628P mutations are associated with an increased risk of Parkinson's disease in the Malaysian population," BioMed Research International, vol. 2014, Article ID 867321, 4 pages, 2014.

[15] S. N. Pchelina, A. F. Yakimovskii, O. N. Ivanova, A. K. Emelianov, A. H. Zakharchuk, and A. L. Schwarzman, "G2019S LRRK2 mutation in familial and sporadic Parkinson's disease in Russia," Movement Disorders, vol. 21, no. 12, pp. 2234-2236, 2006.

[16] M. J. Farrer, J. T. Stone, C.-H. Lin et al., "Lrrk2 G2385R is an ancestral risk factor for Parkinson's disease in Asia," Parkinsonism \& Related Disorders, vol. 13, no. 2, pp. 89-92, 2007.

[17] H. C. Fung, C. M. Chen, J. Hardy, A. B. Singleton, and Y. R. Wu, "A common genetic factor for Parkinson disease in ethnic Chinese population in Taiwan," BMC Neurology, vol. 6, p. 47, 2006.

[18] E. K. Tan, Y. Zhao, L. Skipper et al., "The LRRK2 Gly2385Arg variant is associated with Parkinson's disease: genetic and functional evidence," Human Genetics, vol. 120, no. 6, pp. 857-863, 2007.

[19] W. Liu, Z. Zeng, J. Li, X. Liu, M. Bo, and H. Lv, "The association between LRRK2 G2385R and phenotype of Parkinson's disease in asian population: a meta-analysis of comparative studies," Parkinsons Disease, vol. 2018, Article ID 3418306, 7 pages, 2018.

[20] I. F. Mata, J. M. Kachergus, J. P. Taylor et al., "Lrrk2 pathogenic substitutions in Parkinson's disease," Neurogenetics, vol. 6, no. 4, pp. 171-177, 2005.

[21] X.-K. An, R. Peng, T. Li et al., "LRRK2 Gly2385Arg variant is a risk factor of Parkinson's disease among Han-Chinese from mainland China," European Journal of Neurology, vol. 15, no. 3, pp. 301-305, 2008.

[22] S. Shojaee, F. Sina, N. Farboodi et al., "A clinic-based screening of mutations in exons 31, 34, 35, 41, and 48 ofLRRK2in Iranian Parkinson's disease patients," Movement Disorders, vol. 24, no. 7, pp. 1023-1027, 2009.

[23] O. A. Ross, I. A. Soto-Ortalazo, M. G. Heckman et al., "Genetic epidemiology of Parkinson's disease consortium (2011) association of LRRK2 exonic variants with susceptibility to
Parkinson's disease: a case-control study," The Lancet Neurology, vol. 10, pp. 898-908, 2011.

[24] C. P. Zabetian, M. Yamamoto, A. N. Lopez et al., "LRRK2mutations and risk variants in Japanese patients with Parkinson's disease," Movement Disorders, vol. 24, no. 7, pp. 1034-1041, 2009.

[25] J. P. Rubio, S. Topp, L. Warren et al., "Deep sequencing of theLRRK2gene in 14,002 individuals reveals evidence of purifying selection and independent origin of the p.Arg1628Pro mutation in Europe," Human Mutation, vol. 33, no. 7, pp. 1087-1098, 2012.

[26] K. Li, B. Tang, Z. H Liu et al., "LRRK2 A419V variant is a risk factor for Parkinson's disease in Asian population," Neurobiol Aging, vol. 36, pp. 2908-2905, 2015.

[27] K. Nuytemans, B. Meeus, D. Crosiers et al., "Relative contribution of simple mutations vs. copy number variations in five Parkinson disease genes in the Belgian population," Human Mutation, vol. 30, no. 7, pp. 1054-1061, 2009.

[28] E. K. Tan, R. Peng, Y. Y. Teo et al., "Multiple LRRK2 variants modulate risk of Parkinson disease: a Chinese multicenter study," Human Mutation, vol. 31, pp. 561-568, 2010.

[29] N. N. Li, E. K. Tan, X. L. Chang et al., "Genetic analysis of LRRK2 A419V variant in ethnic Chinese," Neurobiology of Aging, vol. 33, pp. 1849-1843, 2012.

[30] Y. R. Wu, L. C. Tan, X. Fu et al., "LRRK2 A419V is not associated with Parkinson's disease in different Chinese populations," PLoS One, vol. 7, Article ID e36123, 2012.

[31] A. A. Gopalai, S. Y. Lim, Z. A. Aziz et al., "Lack of association between the LRRK2 A419V variant," Annals Academy of Medicine Singapore, vol. 42, pp. 237-240, 2013.

[32] M. G. Heckman, A. I. Soto-Ortolaza, J. O. Aasly et al., "Genetic epidemiology of Parkinson's disease (GEO-PD) consortium (2013) population specific frequencies for LRRK2 susceptibility variants in the genetic epidemiology of Parkinson's disease (GEO-PD) consortium," Movement Disorders, vol. 28, pp. 1740-1744, 2013.

[33] Y.-H. Wu-Chou, Y.-T. Chen, T.-H. Yeh et al., "Genetic variants of SNCA and LRRK2 genes are associated with sporadic PD susceptibility: a replication study in a Taiwanese cohort," Parkinsonism \& Related Disorders, vol. 19, no. 2, pp. 251-255, 2013.

[34] H. Zhao and Z. Kong, "Relationship between LRRK2 R1628P polymorphism and Parkinson's disease in Asian populations," Oncotarget, vol. 7, pp. 46890-46898, 2016. 